\title{
Author's reply to the letter to the editor of Journal of the Korean Association of Oral and Maxillofacial Surgeons
}

\author{
Atef Abdel Hameed Fouda \\ Department of Maxillofacial Surgery, Kasr El Eyne Hospital, Cairo University, Cairo, Egypt
}

\section{Dear Editor,}

I appreciate the letter presented by Costa et al. ${ }^{1}$ regarding the recently published review article ${ }^{2}$.

First of all, as stated in "9.1.3 Why perform a meta-analysis in a review?" of "Cochrane Handbook for Systematic Reviews of Interventions",3, presence of more than author is optional to decrease selection bias not an obligatory to accept or refuse the review because it is very common to let third one to remove the conflict or use other statistical means to accept or reject the paper that I think that the reviewer of the article proficiently can play that role.

Also, Fig. 1 is an image from "page 88 " of the review ${ }^{2}$ and you notice the systematic PICO very clear in subtitles.

Finally, divide the follow-up period according to the heterogeneity between studies. When heterogeneity found you should divide into subgroups as short period-intermediate period and long period follow up and we all know that splint wearing period affect muscles and habits so we should differentiate the results according to the period of wearing I think no problem in that division specially the results becomes more clear.

Thank you for refer.

Thank you for your effort.

Any further announcement is welcomed.

2. Population
Patients with myofascial pain and/or disk displacement
with or without reduction were included. Patients with arthri-
tis or neuralgias were excluded.
3. Intervention
The study included all types of splints (stabilizing splint,
Michigan splint, centric relation appliance, flat occlusal ap-
pliance, soft or hard splints, vinyl appliances, and positioning
splints).
4. Control group
The patients in the control group underwent medical treat-
ment, biofeedback, non-occluding splints, massages, behav-
ioral therapy, cognitive, counseling, or no treatment.
5. Outcome
1) Primary outcome
Pain intensity was estimated with any recognized, vali-
dated pain scale: visual analogue scale, numeric rating scale,
characteristic pain intensity, and symptom severity index.
subgroup analyses were carried out for the outcomes based
on the follow-up duration classified into one, two, three, six,
and twelve months.

Fig. 1. Image showing the inclusion of four items of PICO (Population, Interventions, Comparators, Outcomes) in the review article 2 . Atef Abdel Hameed Fouda: Author's reply to the letter to the editor of Journal of the Korean Association of Oral and Maxillofacial Surgeons. J Korean Assoc Oral Maxillofac Surg 2020

\section{Author's Contributions}

The manuscript was written by A.A.H.F.

\section{Conflict of Interest}

No potential conflict of interest relevant to this article was reported.

\section{References}

1. Costa MSC, Costa SMS, Freitas NR, Guerrini LB, Ferraz CS, Almeida ALPF. Questions about "No evidence on the effectiveness of oral splints for the management of temporomandibular joint dysfunction pain in both short and long-term follow-up systematic reviews and meta-analysis studies". J Korean Assoc Oral Maxillofac 
Surg 2020;46:367-8. https://doi.org/10.5125/jkaoms.2020.46.5.367

2. Fouda AAH. No evidence on the effectiveness of oral splints for the management of temporomandibular joint dysfunction pain in both short and long-term follow-up systematic reviews and metaanalysis studies. J Korean Assoc Oral Maxillofac Surg 2020;46:8798. https://doi.org/10.5125/jkaoms.2020.46.2.87

3. Higgins JPT, Green S. Cochrane handbook for systematic reviews of interventions (version 5.1.0) [Internet]. London: The Cochrane Collaboration [updated 2011 Mar; cited 2019 Mar 25]. Available from: https://handbook-5-1.cochrane.org.
How to cite this article: Fouda AAH. Author's reply to the letter to the editor of Journal of the Korean Association of Oral and Maxillofacial Surgeons. J Korean Assoc Oral Maxillofac Surg 2020;46:369-370. https://doi.org/10.5125/jkaoms.2020.46.5.369 